\title{
Removal of Zn(II) from Aqueous Acetate Solution Using Di (2-Ethylhexyl) Phosphoric Acid \& Tributylphosphate
}

\author{
Brahim Guezzen ${ }^{1} \&$ Mohamed Amine Didi ${ }^{1}$ \\ ${ }^{1}$ Laboratory of Separation and Purification technology, Department of Chemistry, Faculty of Science, University \\ of Tlemcen, Tlemcen, Algerie \\ Correspondence: Mohamed Amine Didi, Laboratory of Separation and Purification technology, Department of \\ Chemistry, Faculty of Science, University of Tlemcen, B. P. 119-13000 Tlemcen, Algerie. Tel: 213-552-639-237. \\ E-mail: madidi13@yahoo.fr
}

\begin{tabular}{|c|c|c|}
\hline Received: February 13, 2012 & Accepted: February 29, 2012 & Online Published: May 27, 2012 \\
\hline doi. $105539 /$ iic v4n3n32 & IRL $\cdot \mathrm{httn} \cdot / \mathrm{dx}$ doi $\operatorname{ror} / 10$ & iic. $v 4 n 3 n 32$ \\
\hline
\end{tabular}

\begin{abstract}
The extraction of Zinc (II) in acetate medium with di (2-ethylhexyl) phosphoric acid (D2EHPA) in chloroform diluent was investigated under different experimental conditions, in order to have a better understanding of the extraction mechanism. The extraction yield was found to depend on the concentrations of Zinc (II) and D2EHPA, and the equilibrium $\mathrm{pH}$. The effects of acetic acid and the salting-out agent were also studied.

The nature of the extracted species was investigated by the slope analysis method. Graphs of $\log \mathrm{D}$ vs. $\log$ [D2EHPA] and $\log \mathrm{D}$ vs. $\mathrm{pH}$ were plotted for $\mathrm{Zn}$ (II), and the species extracted into the organic phase was found to have the composition $\left(\mathrm{ZnCH}_{3} \mathrm{COO}\right) \mathrm{R}$.HR.

The best performance was reached $(80 \%)$ with zinc concentrations lower than $5 \mathrm{mM}$ in a neutral medium. The extraction yield of metals decreased as the acetic acid concentration increased with any given extractant concentration. The addition of sodium acetate to the aqueous phase strongly increased the zinc extraction yield (99.5\%).
\end{abstract}

A synergistic effect was observed by the addition of tributhylphosphate (TBP) with the organic phase.

Keywords: desalination, Zinc (II) extraction, D2EHPA, TBP, synergistic effect

\section{Introduction}

Heavy metals, apart from being hazardous for living organisms when exceeding the specific limits, have accumulating characteristics in nature as they cannot be biodegraded (Veli et al., 2007). Zn (II) being in the list of priority pollutants, proposed by the Environmental Protection Agency (EPA), gives rise to serious poisoning cases. The main symptoms of poisoning are dehydration, electrolyte imbalance, stomachache, nausea, dizziness and incoordination in muscles (Jain et al., 2004). These metals can be treated from wastewater by using various physicochemical methods like Adsorption, chemical settling, reverse osmosis and solvent extraction which are the most frequently used methods.

In the Liquid-liquid Extraction Technology, the extractant plays a characteristic role for the separation of metal ions. A suitable choice of the extractant decides the success of the extraction process. Several extractants were developed and their properties of extraction were evaluated for various metal ions (Reynier et al., 1998).

Acid organophosphorus compounds are excellent extractants. They are particularly used for the purification of the liquid effluents likely to contain heavy metals (Ritcey et al., 1979).

Numerous extractants, such as tributylphosphate (Singh et al., 1980), trioctylphosphine oxide (Matsui et al., 1979), tri-n-butoxyethylphosphate, (carboxy-2-ethyl) diphenylphosphine oxide (Rocca et al., 1971), triphenyl-phosphine oxide (Raman et al., 1989), have been used for the Liquid-liquid Extraction of Zn(II).

Di (2-ethylhexyl) phosphoric acid is available commercially. It has been widely used in the extraction of a range of metals including nickel, cobalt, copper, chromium and bismuth (Nasr-Eddine Belkhouche et al., 2010).

In recent years, the extraction equilibrium of zinc (II) with D2EHPA has been characterized by many investigators. Shiri-Yekta et al. (2009) have studied the separation of zinc, cadmium and lead ions by D2EHPA dissolved in cyclohexane. Mellah et al. (2006) reported the solvent extraction of zinc and cadmium from a phosphoric acid solution using D2EHPA diluted in kerosene, and proposed some compounds, such as $\mathrm{ZnA}_{2}$ 
(HA) org and $\mathrm{CdA}_{2}(\mathrm{HA})_{1 / 2}$ org , in organic form.

The Recovery of zinc sulphate from industrial effluents by liquid-liquid extraction using D2EHPA was investigated by (Dayrell Pereira et al., 2007). Synergistic extraction systems have been applied to heavy metals and rare-earths to enhance the extraction efficiency and separation factors, and thus the effects of TBP as phase modifier and synergist agent for the separation of metals has been widely reported (Eivazi et al., 2008; Yun et al., 1985).

In the present paper, a solvent extraction process has been developed for the removal of $\mathrm{Zn}$ (II). The organic solvent, di (2-ethylhexyl) phosphoric acid in chloroform diluents, was used for the extraction of zinc from an aqueous acetate medium in one step. Different process parameters, viz. effect of time, concentration of extractants, $\mathrm{O} / \mathrm{A}$ molar ratio, equilibrium $\mathrm{pH}$, etc. were also optimized. Synergy was also investigated by addition of tributylphosphate.

\section{Experimental}

\subsection{Reagents}

Zinc acetate dehydrates, acetic acid, chloroform and di (2-ethylhexyl) phosphoric acid were purchased from Fluka. The tributhylphosphate provided from Aldrich.

\subsection{Extraction}

The extraction/stripping experiments were performed by stirring the appropriate extractant quantity and aqueous solution $(10 \mathrm{~mL})$ for $30 \mathrm{~min}$, followed by an aqueous-organic phase separation.

The aqueous phases were analyzed with a Perkin-Elmer atomic absorption spectrophotometer assisted by micro - computer (Model A Analyst 300) before and after extraction.

The $\mathrm{pH}$ of the aqueous solution was adjusted by adding small amounts of $\mathrm{HCl}$ or $\mathrm{NaOH}$. After phase separation, the equilibrium $\mathrm{pH}$ was measured with a Consort $\mathrm{C} 831 \mathrm{pH}$ meter. All the distribution equilibrium studies were carried out at $20 \pm 1^{\circ} \mathrm{C}$.

\subsection{Evaluation}

The extraction experiments results are discussed in term of extraction yield (Y) and distribution ratio (D) defined as follows:

$$
\begin{gathered}
Y(\%)=\left(m_{i}-m_{f}\right) / m_{i} \\
D=\left(V_{a q} / V_{o r g}\right) \cdot\left(m_{i}-m_{f}\right) / m_{f}
\end{gathered}
$$

where: $\mathrm{m}_{\mathrm{i}}=$ initial mass of $\mathrm{Zn}^{2+}$ in aqueous phase; $\mathrm{m}_{\mathrm{f}}=$ mass of $\mathrm{Zn}^{2+}$ after extraction; $\mathrm{V}_{\mathrm{aq}}=$ the volume of the aqueous phase; $\mathrm{V}_{\text {org }}=$ the volume of the organic phase.

\section{Results and Discussion}

\subsection{Effect of Contact Time}

The extraction experiments were carried out for contact times ranging from 5 to $50 \mathrm{~min}$. The operating conditions of extraction were: $[\mathrm{D} 2 \mathrm{EHPA}]=0.05 \mathrm{M},[\mathrm{Zn}(\mathrm{II})]=0.01 \mathrm{M}, \mathrm{A} / \mathrm{O}$ phase ratio $=1$. The results are presented in Figure 1 . The extraction yield was $69.5 \%$ after $30 \mathrm{~min}$.

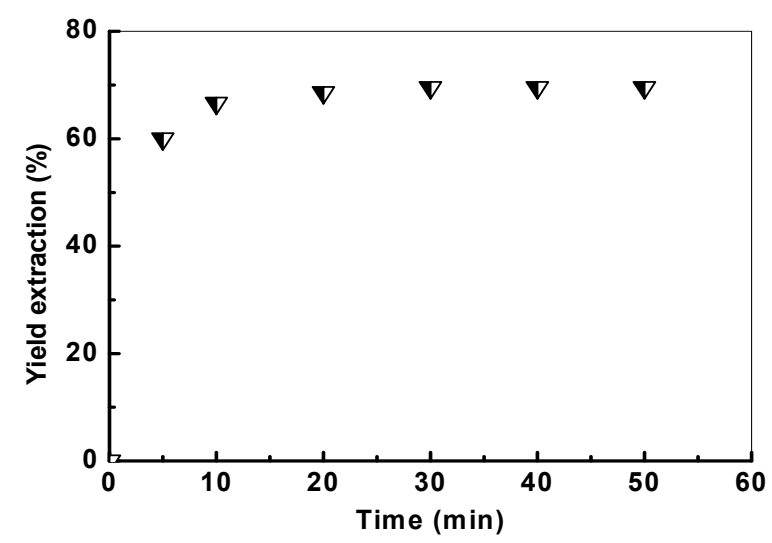

Figure 1. Determination of the equilibrium time of zinc extraction 


\subsection{Effect of O/A Molar Ratio}

The $\mathrm{O} / \mathrm{A}$ molar ratio was varied between 0.2 and $20, \mathrm{~A} / \mathrm{O}$ volumetric ratio $=1$. The results are shown in Figure 2 . The extraction yield increased while increasing the O/A molar ratio, for $0.05 \mathrm{M}$ of D2EHPA concentration $\left(\mathrm{Y}_{\max }=\right.$ $83.53 \%)$. On the other hand, the maximum of the extraction yield is reached for a value of $\mathrm{O} / \mathrm{A}$ equal to $1\left(\mathrm{Y}_{\max }=\right.$ $51.17 \%$ ) for $0.01 \mathrm{M}$ of D2EHPA concentration.

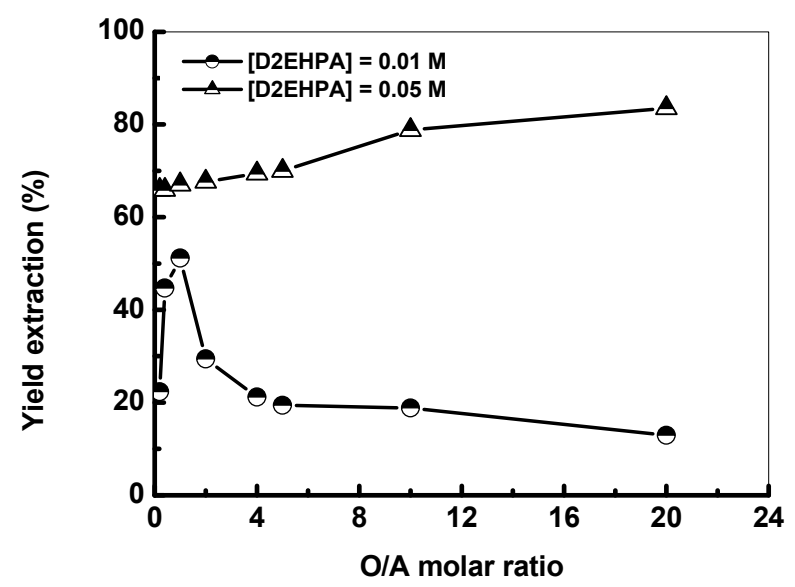

Figure 2. Influence of the $\mathrm{O} / \mathrm{A}$ molar ratio on the extraction yield

The effect of the initial zinc concentration on the extraction yield was studied in the range $0.001 \mathrm{M}-0.05 \mathrm{M}$ (Figure 3). It was observed that the D2EHPA $(0.05 \mathrm{M})$ gives a better extraction for concentrations lower than $0.005 \mathrm{M}$.

For a concentration of $0.01 \mathrm{M}$ in D2EHPA, the extraction yield increases from 18.8 to $51.2 \%$ in the initial zinc concentration range $0.001-0.01 \mathrm{M}$, and then decreases.

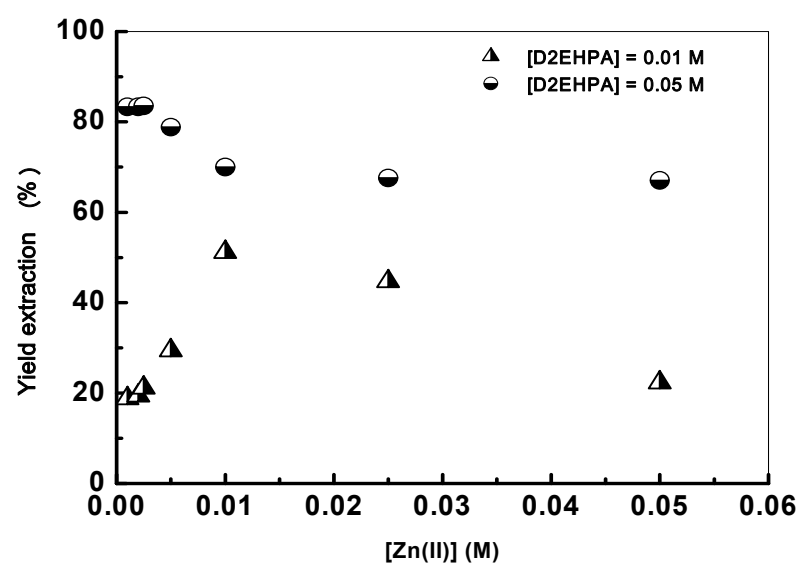

Figure 3. Influence of the initial zinc concentration on the extraction yield

\subsection{Effect of D2EHPA Concentration}

The effect of the concentration of D2EHPA on the extraction yield was studied in the range 0.001- $0.05 \mathrm{M}$, at an equilibrium $\mathrm{pH}$ equal to 3.0. It was observed that the extraction yield increases with the extractant concentration ( Figure 4). Beyond $0.02 \mathrm{M}$, the extractant concentration had no effect on the yield extraction. 


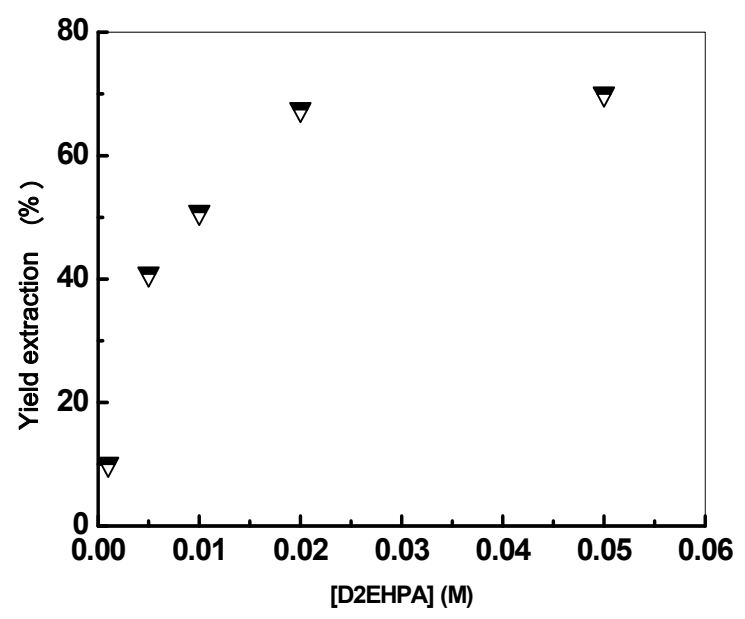

Figure 4. Effect of the D2EHPA concentrations on the zinc extraction

\subsection{Effect of Equilibrium $\mathrm{pH}$}

The experimental studies on zinc extraction were carried out using organic feed concentrations of $0.005 \mathrm{M}$ and $0.01 \mathrm{M}$ D2EHPA respectively, with a fixed concentration of zinc at $0.01 \mathrm{M}$. The extraction yield increases as the pHe increases ( Figure 5). This could be explained by the fact that in the $\mathrm{pH}_{\mathrm{e}}$ range $(2.8-4.5)$, the extraction was governed by the cation exchange reaction, in which the protons are released (Miralles et al., 1992).

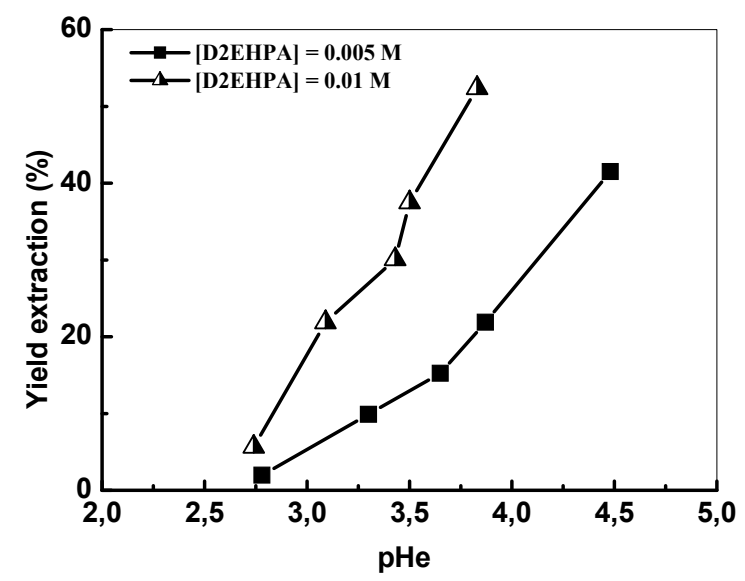

Figure 5. Variation of equilibrium $\mathrm{pH}$ on the yield extraction

\subsection{Determination of the Metal-organic Complex Species}

The cation exchange is the principal mode of action of D2EHPA during the extraction reaction. The oxygen atom of the phosphoryl group $\mathrm{P}=\mathrm{O}$ ensures coordination with the ions extracted by forming chelating products (Mellah et al., 2006). It also plays an important role when the extraction is carried out, starting from the strongly acidic aqueous solutions, since D2EHPA behaves like a solvating agent. A dimer state of D2EHPA has been considered, as reported by various authors (Mellah et al., 2006; Alamdari et al., 2004; Mansur et al., 2002). The dimerization constant of D2EHPA is about $10^{6}$, in polar solvents, and the equation of the dimerized form can be written in the following way:

$$
2(H R)_{\text {org }} \rightarrow\left(H_{2} R_{2}\right)_{\text {org }}
$$

Thus, the mechanism for the solvent extraction of zinc by D2EHPA in chloroform can be represented as follows (Mansur et al., 2002): 


$$
M_{a q}^{n+}+\left(\frac{n+p}{2}\right)\left(H_{2} R_{2}\right)_{o r g} \rightarrow M R_{n}(H R)_{p o r g}+n H_{a q}^{+}
$$

where $\left(\mathrm{H}_{2} \mathrm{R}_{2}\right)$ is the extractant in dimeric form, M the metal, $n$ the valency of the metal or metal complex ion and $p$ the number of molecules of extractant engaged in the reaction. The equilibrium constant of the extraction reaction $\mathrm{K}_{\mathrm{ex}}$, can be given as a function of molar concentration, provided that the ionic strength of the aqueous solution is constant.

$$
K_{e x}=\frac{\left[M R_{n}(H R)_{p}\right]_{o r g}\left[H^{+}\right]_{a q}{ }^{n}}{\left[M^{n+}\right]_{a q}\left[H_{2} R_{2}\right]_{o r g}{ }^{(n+p) / 2}}
$$

The distribution coefficient $D=\frac{\left[\boldsymbol{M} \boldsymbol{R}_{n}(\boldsymbol{H R})_{p}\right]_{\text {org }}}{\left[\boldsymbol{M}^{n+}\right]_{a q}}$ is substituted into Eq. (5):

$$
D=\frac{K_{e x}\left[H_{2} R_{2}\right]_{o r g}{ }^{(n+p) / 2}}{\left[H^{+}\right]_{a q}}
$$

Taking the logarithm of the above equation, one obtains:

$$
\log D=\log K_{e x}+\left(\frac{n+p}{2}\right) \log \left[H_{2} R_{2}\right]_{\text {org }}+n p H
$$

The stoichiometric coefficients for the extraction reaction can be determined from the intercept of the plot of $\log D$ vs. $\log \left[\mathrm{H}_{2} \mathrm{R}_{2}\right]_{\text {org }}$ and $\log D$ versus equilibrium $\mathrm{pH}$.

Figure 6 shows the relation between $\log D$ and the equilibrium $\mathrm{pH}$, depending on the concentration of D2EHPA. The average value of $n$, calculated from the slope of the straight line, is 1 , irrespectively of the concentration of D2EHPA. Figure 7 shows a plot of $\log$ D vs. $\log$ [D2EHPA] at equilibrium $\mathrm{pH} 3.0$, which means that zinc extraction is linearly related to the extractant concentration. The slope value $(n+p) / 2$ was found to be $\sim 1$, which means that $\mathrm{p}$ is equal to 1 . The extraction mechanism in acetate medium by D2EHPA diluted in chloroform may be represented as:

$$
\begin{aligned}
& \boldsymbol{K}_{e x} \\
& \left(\mathrm{ZnCH}_{3} \mathrm{COO}\right)^{+}{ }_{\mathrm{aq}}+\left[\mathrm{H}_{2} \mathrm{R}_{2}\right]_{\mathrm{org}} \rightarrow\left[\left(\mathrm{ZnCH}_{3} \mathrm{COO}\right) \mathrm{R} . \mathrm{HR}\right]_{\mathrm{org}}+\mathrm{H}_{\mathrm{aq}}^{+}
\end{aligned}
$$

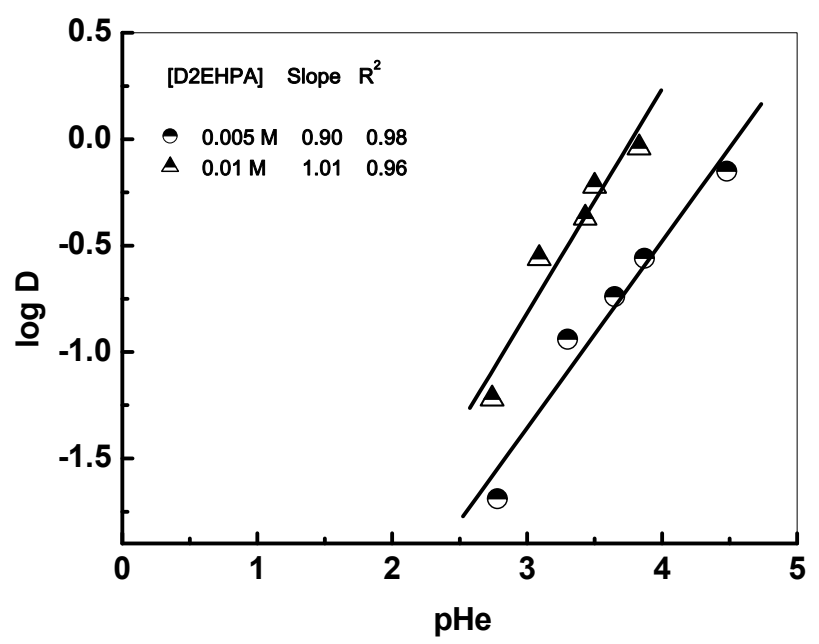

Figure 6. Effect of the equilibrium $\mathrm{pH}$ on the distribution coefficient of zinc 


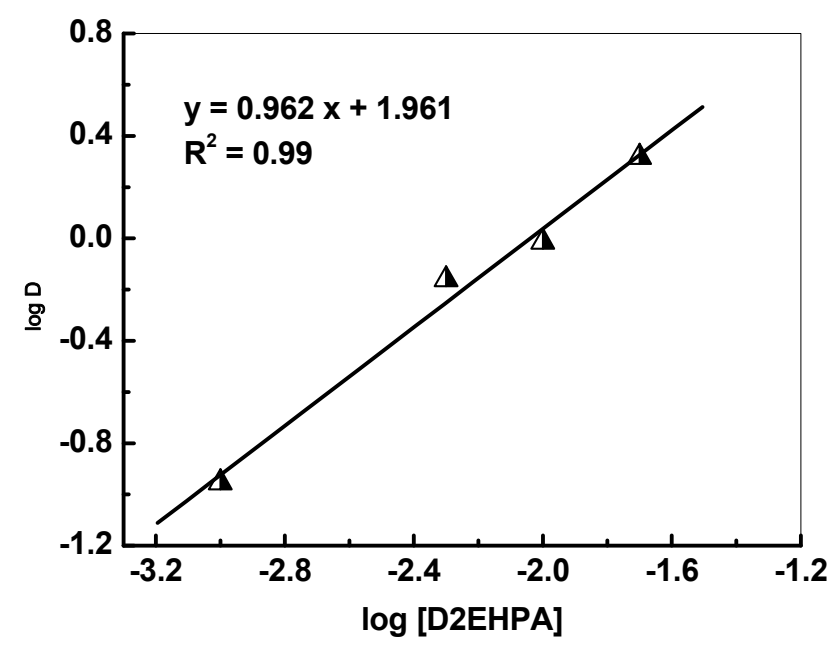

Figure 7. Effect of extractant concentration on the distribution coefficient of zinc

\subsection{Effect of Acid Concentration on Zinc Extraction}

In order to compare the capacity of our extractant before being studied in a neutral medium (without addition), we carried out the extraction of zinc in a slightly acid medium by addition of $\mathrm{CH}_{3} \mathrm{COOH}$. Solutions of zinc acetate $(0.01 \mathrm{M})$ and acetic acid $(0.05,0.1$ and $0.2 \mathrm{M})$ were prepared. For each solution, one carries out extractions for various concentrations in D2EHPA, going from $0.001 \mathrm{M}$ up to $0.05 \mathrm{M}$.

From the results given in Figure 9, we notice that the quantity of extracted zinc (II) decreases with the increase of the added $\mathrm{CH}_{3} \mathrm{COOH}$ quantity to the metal aqueous phase. The acetate acid has an antagonistic effect on extraction. An extraction yield of zinc of $67.5 \%$ (in absence of acid) and $33.33 \%$ (in presence of acid) were obtained for a concentration of $0.02 \mathrm{M}$ in D2EHPA. This is explained by the fact that the $\mathrm{H}^{+}$ions of acid being in excess in the aqueous phase results in an equilibrium shift to the left (Eq. 9), which leads to a decrease in metal ions extraction.

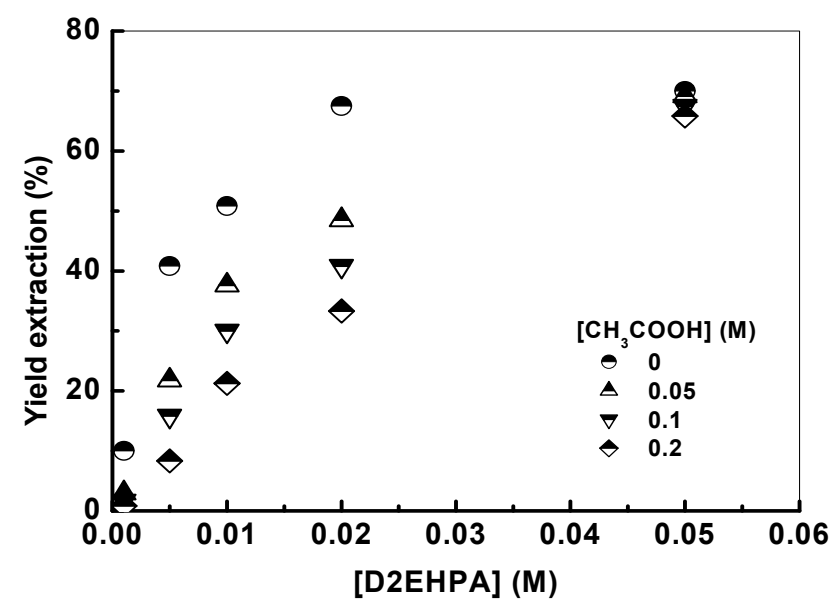

Figure 8. Effect of acetic acid on the zinc extraction

\subsection{Effect of Sodium Acetate on Zinc Extraction}

The influence of ionic-strength on zinc extraction by the D2EHPA solution was studied in presence of $\mathrm{CH}_{3} \mathrm{COONa}$, at various concentrations $(0.05,0.1$ and $0.2 \mathrm{M})$ with a constant concentration of $0.01 \mathrm{M}$ of zinc. The D2EHPA concentration was taken in the range $0.001-0.05 \mathrm{M}$. 
Figure 9 shows that the addition of sodium acetate in the aqueous phase strongly increases the zinc extraction yield (from 70 to $99.5 \%$ ). However, increasing the concentration of sodium acetate from 0.05 to $0.2 \mathrm{M}$ had little influence on the extraction percentage. Thus, one can affirm that the extraction of zinc (II) by D2EHPA depends on the ionic-strength in an aqueous medium until saturation. The results of extraction yield previously obtained in the various mediums are represented in Figure 10.

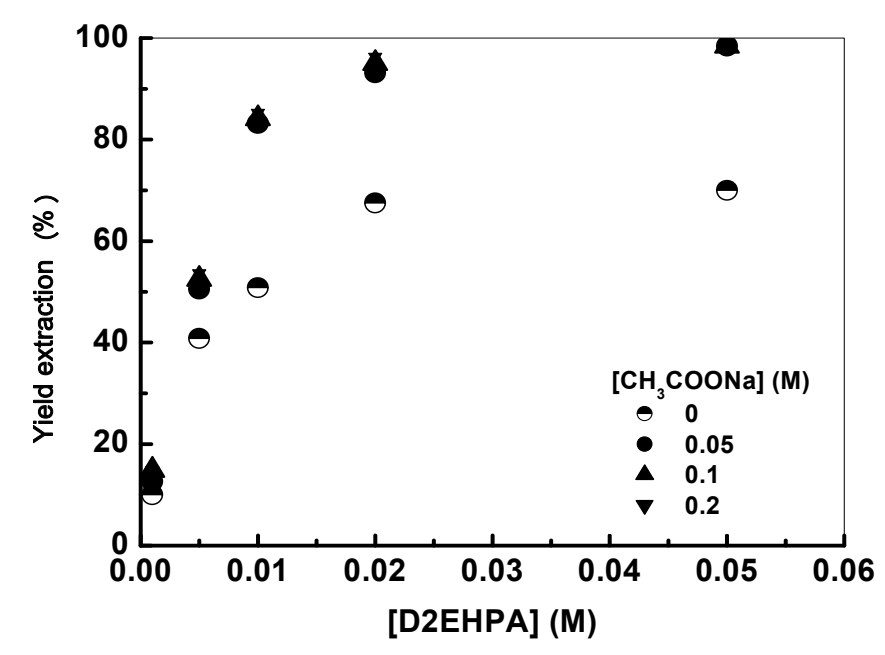

Figure 9. Effect of sodium acetate on the zinc extraction

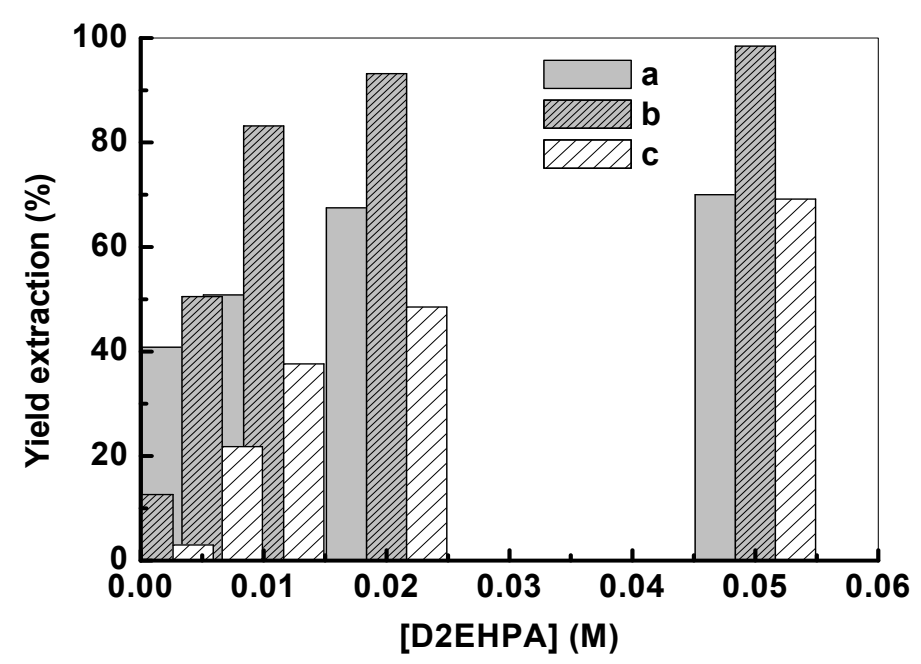

Figure 10. Effect of D2EHPA concentration on zinc extraction in various mediums

a: $\mathrm{Zn}$ (II) (without addition), b: Zn (II) $+0.05 \mathrm{M}$ of acetic acid, c: $\mathrm{Zn}(\mathrm{II})+0.05 \mathrm{M}$ of sodium acetate

\subsection{Synergistic Effect of TBP}

Under certain well defined conditions, the mixture of two extractants can lead to the extraction of certain metals stronger than those produced by a separate action.

The only systems of practical interest combine the action of an exchanger of cations (dialkylphosphoric acid) and a solvator (neutral phosphate). To quantify the synergic effect, the synergic coefficient (S.C.) was defined as:

$$
\text { S.C. }=\log \left[\frac{D_{1,2}}{D_{1}+D_{2}}\right]
$$

where $\mathrm{D}_{1,2}, \mathrm{D}_{1}$ and $\mathrm{D}_{2}$ are the distribution ratio of zinc using the synergistic mixture and the individual extractants, respectively (Kraikaew et al., 2005). 
If S.C. is $>0$, a positive synergic effect is said to occur. If there is an antagonistic effect (negative synergism), then S.C. $<0$. If there is no synergic effect, S.C. $=0$.

The S.C. of the mixed extractant systems was utilized to study the extraction behavior of zinc (II) in three aqueous phase media: i) neutral medium $\left(\mathrm{Zn}^{2+}\right.$ without addition), ii) acid medium $\left(\mathrm{Zn}^{2+}\right.$ with acetic acid) and iii) acetate medium $\left(\mathrm{Zn}^{2+}\right.$ with sodium acetate).

The experiments were carried out keeping the concentrations of TBP $(0.001,0.01$ and $0.02 \mathrm{M})$ constant while varying those of the organophosphorus extractant (D2EHPA) in the range [0.001-0.01 M].

The experimental data of the synergistic systems are presented in Table 1. The S.C. values are positive for the three mediums. One can notice that the synergic coefficients decrease with the increase of D2EHPA concentration. However, the synergic coefficients increase with the increase of TBP concentration. To confirm these results, the curve representing the variation of S.C. versus D2EHPA /TBP molar ratio was plotted in (Figure 11). Thus, it is clear that the S.C. decreases with the increase of the molar ratio.

Table 1. Distribution coefficient values of zinc (II) with mixed extractants

\begin{tabular}{|c|c|c|c|c|c|c|c|c|c|c|c|c|c|}
\hline \multirow{2}{*}{$\begin{array}{c}{[\mathrm{TBP}]} \\
(\mathrm{M})\end{array}$} & \multirow[t]{2}{*}{$\begin{array}{c}{[\mathrm{D} 2 \mathrm{EHPA}]} \\
(\mathrm{M})\end{array}$} & \multicolumn{4}{|c|}{$\begin{array}{l}\text { Neutral medium (without } \\
\text { addition, } \quad \mathrm{pH}_{\mathrm{i}}=5.95 \text { ) }\end{array}$} & \multicolumn{4}{|c|}{$\begin{array}{l}\text { Acid medium }(\mathrm{Zn}(\mathrm{II})+ \\
\left.\text { acetic acid, } \quad \mathrm{pH}_{\mathrm{i}}=4.05\right)\end{array}$} & \multicolumn{4}{|c|}{$\begin{array}{l}\text { acetate medium }(\mathrm{Zn}(\mathrm{II})+ \\
\left.\text { sodium acetate, } \mathrm{pH}_{\mathrm{i}}=8.00\right)\end{array}$} \\
\hline & & $\mathrm{D}_{1}$ & $\mathrm{D}_{2}$ & $\mathrm{D}_{1,2}$ & S.C. & $\mathrm{D}_{1}$ & $\mathrm{D}_{2}$ & $\mathrm{D}_{1,2}$ & S.C. & $\mathrm{D}_{1}$ & $\mathrm{D}_{2}$ & $\mathrm{D}_{1,2}$ & S.C. \\
\hline \multirow{3}{*}{$10^{-3}$} & $10^{-3}$ & & 0.109 & 0.163 & 0.137 & & 0.031 & 0.063 & 0.187 & & 0.174 & 0.312 & 0.206 \\
\hline & $5.10^{-3}$ & 0.010 & 0.683 & 0.836 & 0.081 & 0.010 & 0.278 & 0.347 & 0.081 & 0.020 & 1.104 & 1.245 & 0.044 \\
\hline & $10^{-2}$ & & 1.019 & 1.196 & 0.065 & & 0.601 & 0.803 & 0.119 & & 5.313 & 5.734 & 0.031 \\
\hline \multirow{3}{*}{$10^{-2}$} & $10^{-3}$ & & 0.109 & 0.188 & 0.128 & & 0.031 & 0.086 & 0.227 & & 0.174 & 0.347 & 0.186 \\
\hline & $5.10^{-3}$ & 0.031 & 0.683 & 0.905 & 0.103 & 0.020 & 0.278 & 0.384 & 0.110 & 0.052 & 1.104 & 1.296 & 0.050 \\
\hline & $10^{-2}$ & & 1.019 & 1.245 & 0.074 & & 0.601 & 0.870 & 0.146 & & 5.313 & 5.734 & 0.029 \\
\hline \multirow{3}{*}{$2.10^{-2}$} & $10^{-3}$ & & 0.109 & 0.202 & 0.129 & & 0.031 & 0.108 & 0.241 & & 0.174 & 0.365 & 0.189 \\
\hline & $5.10^{-3}$ & 0.041 & 0.683 & 0.942 & 0.114 & 0.031 & 0.278 & 0.485 & 0.196 & 0.062 & 1.104 & 1.525 & 0.117 \\
\hline & $10^{-2}$ & & 1.019 & 1.296 & 0.087 & & 0.601 & 0.980 & 0.191 & & 5.313 & 6.215 & 0.063 \\
\hline
\end{tabular}

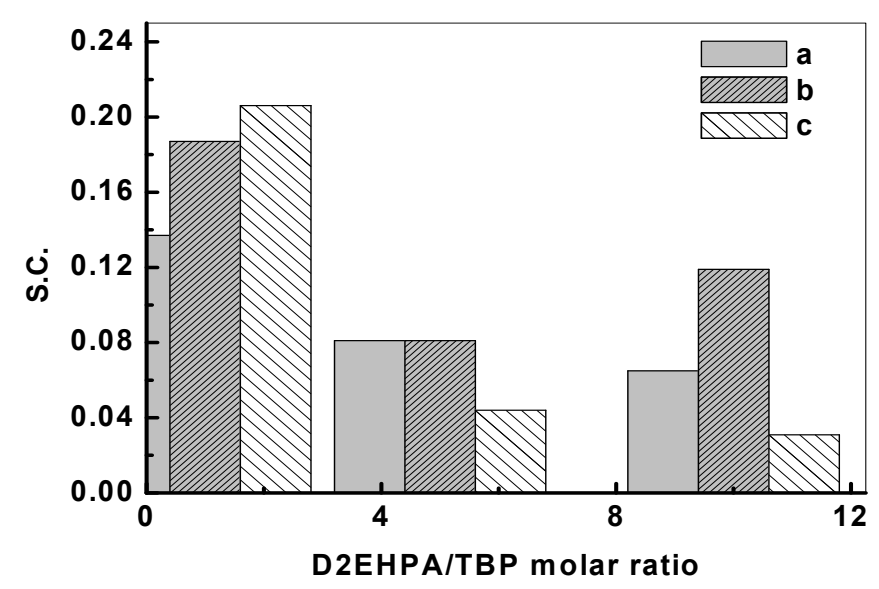

Figure 11. Synergistic extraction of zinc by the mixture of D2EHPA and TBP

a: Zn (II) (without addition), b: Zn (II) with $0.05 \mathrm{M}$ of acetic acid, c: Zn(II) with $0.05 \mathrm{M}$ of sodium acetate

The formation of new bonds in the organic phase between D2EHPA and TBP may be the reason for these synergistic shifts and therefore some extractant molecules are polymerized through hydrogen bonds (Alamdari et 
al., 2002). The results of the FT-IR analysis (Haghshenas Fatmehsari et al., 2009), of a mixture of D2EHPA and TBP as compared to D2EHPA alone, show that the $\mathrm{P}=\mathrm{O}$ vibration band for TBP disappeared and the intensity of this band for D2EHPA decreased.

Therefore, it may be concluded that an interaction between D2EHPA and TBP has occurred, with formation of the intermolecular connections of type RH O = P- (Krea et al., 2000).

It is noticed that the effect of the $\mathrm{pH}$ of the aqueous medium on the synergistic effect is determining.

\section{Conclusion}

A study of the extraction kinetics of zinc (II) from an aqueous acetate solution with D2EHPA in chloroform, showed that the percentage of extracted metal increases with contact time. The extraction equilibrium was reached after $30 \min (69.52 \%)$.

The variation of the O/A molar ratio from 0.2 to 20 led to an increase in the percentage of extracted metal (83.53\%) for $0.05 \mathrm{M}$ of D2EHPA, but for $0.01 \mathrm{M}$, the maximum of extraction yield is reached for a value of O/A equal to $1(51.17 \%)$.

The best extraction of zinc (II) was obtained for a D2EHPA concentration of $0.05 \mathrm{M}$ and a zinc concentration of $0.005 \mathrm{M}$. The extraction percentage increases with an increase in the equilibrium $\mathrm{pH}$ of the aqueous phase. In the $\mathrm{pH}$ range $(2.8-4.5)$, the extraction is governed by the cation exchange reaction in which the protons are released.

In the D2EHPA concentration range $0.001-0.05 \mathrm{M}$, at equilibrium $\mathrm{pH} 3.0$, the percentage of extracted metal increased with an increase of the extractant concentration, and the extraction studies showed the formation of $\left(\left(\mathrm{ZnCH}_{3} \mathrm{COO}\right) \mathrm{R} . \mathrm{HR}\right)_{\text {org }}$ species in the organic feed.

The antagonistic effect on the extraction of $\mathrm{Zn}$ (II) was observed by adding acetic acid, i.e. an extraction yield of zinc of $67.5 \%$ (in absence of acid) down to $33.33 \%$ (with $0.05 \mathrm{M}$ of acid). The presence of sodium acetate at 0.05 $\mathrm{M}$ in aqueous solution of zinc increases the extraction yield from 70.0 to $99.5 \%$. Thus the synergic coefficients decrease with the increase of the D2EHPA/TBP molar ratio.

The $\mathrm{pH}$ has a determinative effect on the increase of the zinc extraction yield and synergistic effect.

\section{Acknowledgements}

We gratefully acknowledge the ANDRU-Algeria and CMEP-TASSILI $\mathrm{N}^{\circ} 10$ MDU 799 for their financial support.

\section{References}

Alamdari, E. K., Moradkhani, D., Darvish, D., Askari, M., \& Behnian, D. (2004). Synergistic effect of MEHPA on co-extraction of zinc and cadmium with DEHPA. J. Miner. Eng., 17, 89-92. http://dx.doi.org/10.1016/j.mineng.2003.10.003

Alamdari, E. K., Darvishi, D., Sadrnezhaad, S. K., Shabestari, Z. M., O'hadizadeh, A., \& Akbari, M. (2002). Effect of TBP as a modifier for extraction of zinc and cadmium with a mixture of DEHPA and MEHPA. In: Sole, K. C., Cole, P. M., Preston, J. S., Robinson, D. J. (Eds.). Proc. Int. Conf. Solvent Extraction Conference. S. Afr. Inst. Min \& Metall., Johannesburg, 1, 1052-1057.

Belkhouche, N., \& Didi, M. A. (2010). Extraction of Bi(III) from nitrate medium by D2EHPA impregnated onto Amberlite XAD-1180. Hydrometallurgy, 103, 60-67. http://dx.doi.org/10.1016/j.hydromet.2010.02.015.

Dayrell Pereira, D., Denise Ferreira Rocha, S., \& Mansur, M. B. (2007). Recovery of zinc sulphate from industrial effluents by liquid-liquid extraction using D2EHPA (di-2-ethylhexyl phosphoric acid). J. Sep. Purif. Technol., 53, 89-96. http://dx.doi.org/10.1016/j.seppur.2006.06.013

Eivazi, A. R. H., Moradkhani, D., Alamdari, E. K., \& Darvishi, D. (2008). Solvent extraction separation of zinc, manganese and cobalt in sulfate solutions by D2EHPA. In: Moyer, B.A. (Ed.), Proc. Int. Solvent Extraction Conference, Tucson. Canadian Inst. Min. \& Metall., Montreal, I, pp. 233-238.

Haghshenas Fatmehsari, D., Darvishi, D., Etemadi, S., Eivazi Hollagh, A. R., Keshavarz Alamdari, E., \& Salardini, A. A. (2009). Interaction between TBP and D2EHPA during $\mathrm{Zn}, \mathrm{Cd}, \mathrm{Mn}, \mathrm{Cu}, \mathrm{Co}$ and $\mathrm{Ni}$ solvent extraction: A thermodynamic and empirical approach. J. Hydrometallurgy, 98, 143-147. http://dx.doi.org/10.1016/j.hydromet.2009.04.010

Jain, C. K., Singhal, D. C., \& Sharma, M. K. (2004). Adsorption of zinc on bed sediment of river Hindon: adsorption models and kinetics. J. Hazard. Mater. B, 114, 231-239. http://dx.doi.org/10.1016/j.jhazmat.2004.09.001 
Kraikaew, J., Srinuttrakul, W., \& Chayavadhanakur, C. (2005). Solvent extraction study of rare earths from nitrate medium by the mixtures of TBP and D2EHPA in kerosene. J. Met. Mat. Min., 15(2), 89-95. http://dx.doi.org/10.1016/s1002-0721(10)606 01-1

Krea, M., \& Khalaf, H. (2000). Liquid-liquid extraction of uranium and Lanthanide From Phosphoric Acid Using A Synergistic DOPP-TOPO Mixture. J. Hydrometallurgy, 58, 215-225. http://dx.doi.org/10.1016/ S0304-386X(00)00129-8

Mansur, M. B., Slater, M. J., \& Biscaia, E. C. (2002). Kinetic analysis of the liquid-liquid test system ZnSO4/D2EHPA/n-heptane. J. Hydrometallurgy, 63, 107-116. http://dx.doi.org/10.1016/S0304-386X(01) 00210-9

Mansur, M. B., Slater, M. J., \& Biscaia, E. C. (2002). Equilibrium analysis of the reactive liquid-liquid test system ZnSO4/D2EHPA/n-heptane. J. Hydrometallurgy, 63, 117-126. http://dx.doi.org/ 10.1016/S0304- 386X(01) 00211-0

Matsui, M., Hirade, T., \& Shigematsu, T. (1979). Nonaqueous Liquid-Liquid Extraction. Extraction of Zinc from Methanol Water Solution of Chloride by Trioctylphosphine Oxide in Decaline. Anal. Lett., 12, 1385-1397. http://dx.doi.org/10.1080/00032717908067928

Mellah, A., \& Benachour, D. (2006). The solvent extraction of zinc and cadmium from phosphoric acid solution by di-2-ethyl hexyl phosphoric acid in kerosene diluents. J. Chem. Eng. Process., 45, 684-690. http://dx.doi.org/10.1016/j.cep.2006.02.004

Miralles, N., Sastre, A. M., Aguilar, M., \& Cox, M. (1992). Solvent extraction of zinc (II) by organophosphorus acids compounds from perchlorate solutions. Solvent Extr. Ion Exc., 10(1), 51-68. http://dx.doi.org/10.1080/ 07366299208918092

Raman, B., \& Shinde, V. M. (1989). Extraction and determination of zinc in pharmaceutical samples. Talanta, 36, 469. http://dx.doi.org/10.1016/0039-9140(89)80230-9

Reynier, N., Dozol, J. F., Saadioui, M., Asfari, Z., \& Vicens, J. (1998). Complexation properties of a new photosensitive calix[4]arene crown ether containing azo unit in the lower rim towards alkali cations. Tetrahedron Let., 39, 6461-6464. http://dx.doi.org/10.1016/S0040-4039(98)00678-9

Ritcey, G. M., \& Ashbrook, A. W. (1979). Solvent Extraction, 2, Ed. Elsevier Scientific Publishing Company, Amesterdam, Netherlands 167.

Rocca, J. L., \& Porthault, M. (1971). Etude de l'extraction liquide-liquide du Zinc(II) et du Cadmium(II) par l'oxyde de (Carboxy-2-ethyl)diphenyl-phosphine en solution dans le chloroforme. Anal. Chim. Acta., 55, 341-348. http://dx.doi.org/10.1016/S0003-2670(01)82386-2

Shiri-Yekta, Z., Zamani, A. A., \& Yaftian, M. R. (2009). Amelioration of extraction-separation efficiency of $\mathrm{Zn}(\mathrm{II}), \mathrm{Cd}(\mathrm{II})$ and $\mathrm{Pb}(\mathrm{II})$ ions with bis(2-ethylhexyl)phosphoric acid in the presence of a water-soluble N4-type Schiff base ligand. J. Sep. Purif. Technol., 66, 98-103. http://dx.doi.org/10.1016/ j.seppur.2008.11.015

Singh, D., Singh, O. V., \& Tandon, S. N. (1980). Extraction of zinc thiocyanate complex by tributyl phosphate in benzene. J. Anal. Chim. Acta., 115, 369-372. http://dx.doi.org/10.1016/S0003-2670(01)93180-0

Veli, S., \& Alyuz, B. (2007). Adsorption of copper and zinc from aqueous solutions by using natural clay, $J$. Hazard. Mater., 149, 226-233. http://dx.doi.org/10.1016/j.jhazmat.2007.04.109

Yun, S. S. (1985). The thermodynamics of synergistic solvent extraction of $\mathrm{Zn}$ (II) with 1phenyl-3-methyl-4-benzoyl-pyrazole-5-one. Polyhedron, 4, 1865-1868. http://dx.doi.org/10.1016/ S0277$5387(00) 86702-9$ 